\section{The evolution and impact of science in tennis: eight advances for performance and health}

\author{
Babette M Pluim
}

\section{INTRODUCTION}

Owing to players such as Maria Sharapova, Serena Wiliams, Rafael Nadal and Roger Federer, tennis has generated a lot of public interest. Tennis players have become superstars, their names being mentioned alongside those of popular musicians and actors. Behind the glamour, however, a lot of hard work is going into improving the quality of the game. The high level of tennis did not happen overnight. Sporting excellence is supported by scientific research in all aspects of the sport. What are the major scientific advances of the past 10 years and what is their impact on the game of tennis?

\section{Player analysis technology}

Specialised equipment ('smart' devices) are now available that have the ability to measure the way the player performs or interacts with his equipment. ${ }^{1}$ This gives objective information that was previously only available from a subjective analysis by the coach. These devices include the KITRIS-KIT, the Babolat Play racket and the PlaySight smart court.

Players now have access to sophisticated coaching information at low cost, even if they have no coach, and this is having a major impact on the sport. The information is of real time (or very close to real

Correspondence to Dr Babette M Pluim, Medical Department, Royal Netherlands Lawn Tennis Association, Displayweg 4, Amersfoort 3821 BT, The Netherlands; b.pluim@knltb.nl time) and is much more detailed than was previously possible. It is also possible to relay this analytical information to spectators and the media which could significantly change the way that these groups interact with tennis.

The development of this player analysis technology is evolving so rapidly that the 2014 Rules of Tennis have been amended to permit International Tennis Federation (ITF)-approved devices to be used during play. The use of the technology is restricted in accordance with the Coaching Rule, which means that players cannot access any coaching information generated by their equipment when coaching is not permitted.

\section{Electronic line-calling}

A particularly noticeable scientific recent advance has been the introduction of an electronic line-calling system in tennis (Hawk-Eye). ${ }^{2}$ This complex system uses 10 high-performance cameras to track the ball and determine where it lands on the court, which is displayed using computer graphics. With the court layout (lines) programmed into the system, Hawk-Eye accurately records the ball impact area. This information can be provided to players, spectators and match umpires in close to real time and is accepted as a definitive answer to the eternal question 'in or out'.

This has had a major impact on the sport with reduced pressure on officials and rapid closure for the players involved in contested points and decisions. Most importantly, it prevents erroneous calls from deciding the outcome of matches.

\section{Biomechanics and video analysis}

Biomechanics has helped tennis coaches to understand the mechanical characteristics of the tennis stroke and to unlock the complex mechanisms by which players develop power and control. While most of the early research involved the tennis serve, recently ground strokes have been analysed. ${ }^{3}$

Important discoveries in this area are (the timing of) the stretch-shortening cycle, the kinetic chain and variability in stroke production (and therefore coaches should vary pace, spin, direction and height of the ball). This has, in turn, enabled coaches to understand the techniques necessary to develop players, and has led to the marketing of a plethora of video analysis systems for tennis to aid this process (eg, Dartfish, Silicon coach).

Coaches have always asked for information on stroke development and it is pleasing to see investigations into which techniques change over time (variant) and those that are similar for the young highperformance players and the professionals (invariant).

\section{Low compression tennis balls}

The introduction of low-compression tennis balls has fundamentally changed the way children and adults learn to play tennis. These are essentially lightweight balls that are easy to hit. As players become more familiar with the basic strokes, they progress to normal-sized balls that are 'soft' (inflated to a lower pressure than normal-coloured red, orange or green) so that the ball flight is slower and the bounce is lower. This gives the intermediate player longer to return the ball, lengthens the rallies and improves the overall experience of the individual in a positive way. 
Very young players (under 10) can also use smaller rackets and play on a smaller court in addition to using the soft balls (eg, the Tenniskids programme in the Netherlands). Using modified courts and balls has a positive effect on increasing the technical proficiency and number and success of shots and facilitates the learning experience of young players. ${ }^{4}$

\section{Sport psychology}

Major strides have also been made in the field of sport psychology. There is now high awareness of the importance of parents of junior tennis players, and parent education programmes have been developed. For coaching beginners and intermediate players, there is much more focus on the motivational climate, as this is highly relevant. High-performance tennis players use a variety of emotional control strategies, as this has been shown to affect performance in a positive way. It has been acknowledged that tennis can play a significant role for social inclusion of players with special needs. And, finally, the health and psychosocial benefits of tennis play a large role for long-term tennis participation.

\section{Injury surveillance}

General knowledge of tennis injuries has increased over the years, but the reported incidence, severity and nature of injuries show great variation between studies. Although some of this variation can be accounted for by different sample populations and conditions, the main reasons are related to the significant variation in injury definition and the disparate methodologies employed by the separate studies. A consensus statement has now been published on the definitions and methodology for recording injuries and illnesses during tennis activities and this should lead to greater consistency in future studies. ${ }^{5}$ The first study that used the standardised definitions and methodology was published in 2012-a 25-year analysis of injury data from the US Open. ${ }^{6}$

Recently, research has explored the links between loading and tennis injuries, although much more work is needed in this area before definite conclusions can be reached. Player track systems could be used in longitudinal cohort studies to investigate the association between risk factors (such as training and match load) and tennis injuries. Randomised controlled trials are needed that examine the effect of injury prevention measures in tennis.

\section{Nutrition}

Recent advances in nutrition have mainly focused on sports with high-energy demands such as cycling and marathon running, but awareness of the benefits of proper nutrition in tennis has increased. Nowadays, most professional players have a well thought out diet before, during and after play that includes fluids, carbohydrates and protein in the right combination for optimal performance and enhanced recovery.

\section{Heat stress}

A number of studies have been performed to investigate the thermoregulatory response of tennis players to heat stress. ${ }^{7-9}$ These show that core body temperature (CBT) can be maintained at a safe level across a wide range of environmental conditions and is determined mainly by the intensity of the exercise and the resulting metabolic rate. When the cooling mechanisms of the body (sweating and cutaneous vasodilation) work normally, thermal equilibrium is reached and maintained after approximately $40 \mathrm{~min}$ of tennis match play. ${ }^{10}$

However, in hot ambient conditions, CBT is determined not only by the metabolic rate, but also by the environmental heat load. ${ }^{3}$ Work by Périard et al, who studied male tennis players during tennis match play in cool $\left(\sim 19^{\circ} \mathrm{C}\right.$ WBGT (wet bulb globe temperature), $22^{\circ} \mathrm{C}$ ) and hot weather $\left(\sim 34^{\circ} \mathrm{C}\right.$ WBGT, $\left.37^{\circ} \mathrm{C}\right)$, showed mean CBTs of $\sim 38.7^{\circ} \mathrm{C}$ under cool and $\sim 39.4^{\circ} \mathrm{C}$ under hot conditions. ${ }^{8}$ In addition, adverse environmental conditions (eg, high air temperature, high humidity, solar radiation and no wind) will result in a high skin temperature and increased thermal discomfort (irrespective of the actual CBT).

As thermal discomfort increases, players decrease the pace of the match, which results in a drop in metabolic rate: an excellent example of autoregulation. Additional measures that players may take to cool their bodies are the use of ventilators, fans, parasols, ice vests, ice towels and cold water. However, the player may be at risk if he is ill (cytokines raise the temperature set point), is severely dehydrated (less circulating blood to the skin and less cooling) or has autonomic dysfunction (high spinal cord injury, less sweating). In these situations, great care needs to be taken to protect the players from potentially life-threatening heat illness.
When to stop play?

Although biological risk is a continuous variable, the reality of sport means that the decision to play or not to play will be dichotomous. Medicine often puts continuous variables into 'cut-offs' (ie, treatment thresholds for most conditions such as cholesterol, blood pressure, osteoporosis by dual-energy X-ray absorptiometry). Currently, it is up to the tournament referee to decide when to stop play but there is no predetermined threshold.

Evidence from the recent Australian Open indicated that there should be an upper limit above which play should be suspended, even for healthy athletes. This upper limit seems to be around an air temperature of $41-43^{\circ} \mathrm{C}$ or a WBGT of $32^{\circ} \mathrm{C}$, if not for the players, at least for the long-suffering spectators!

\section{Knowledge transfer/exchange}

It is important that the available scientific information gets disseminated to the right people. The ITF has developed a sophisticated website for tennis coaches, players and all tennis enthusiasts. This includes information that translates scientific research into plain language and practical information that is readily available. In particular, the Tennis iCoach section (http://tennisicoach.com) contains technical, tactical, physical, mental and medical information.

The Society for Tennis Medicine and Science (STMS) is an international organisation whose mission is to disseminate practical, scientific, tennis-related information in order to optimise the health and performance of tennis players worldwide. They have a website (http://www. stms-web.org), a journal that is published three times a year, and organise biannual conferences.

The International Tennis Performance Association (iTPA) offers research-based tennis-specific performance education and three levels of certification (http://itpatennis.org).

\section{Summary}

Recent advances in many areas of science have directly impacted the way in which tennis is played nowadays and it is anticipated that scientific research will be a major driver for future developments.

Evolution is evident throughout the modern game of tennis and Charles Darwin would undoubtedly be an avid enthusiast of the sport! 
Competing interests None.

Provenance and peer review Commissioned; internally peer reviewed.

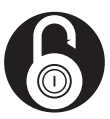

\section{OPEN ACCESS}

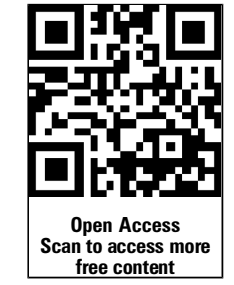

Open Access This is an Open Access article distributed in accordance with the Creative Commons Attribution Non Commercial (CC BY-NC 3.0) license, which permits others to distribute, remix, adapt, build upon this work non-commercially, and license their derivative works on different terms, provided the original work is properly cited and the use is non-commercial. See: http:// creativecommons.org/licenses/by-nc/3.0/

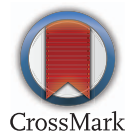

To cite Pluim BM. Br J Sports Med 2014;48:i3-i5. Accepted 23 January 2014

Br J Sports Med 2014;48:i3-i5.

doi:10.1136/bjsports-2014-093434

\section{REFERENCES}

1 ITF Tennis-technical. Player analysis: overview. http://www.itftennis.com/technical/player-analysis/ overview.aspx (accessed 20 Jan 2014).

2 Hawk-Eye. http://www.hawkeyeinnovations.co.uk/ page/sports-officiating/tennis (accessed 20 Jan 2014).

3 Reid M, Elliott B, Crespo M. Mechanics and learning practices associated with the tennis forehand: a review. I Sports Sci Med 2013;12:225-31.
4 Larson EJ, Guggenheimer JD. The effects of scaling tennis equipment on the forehand groundstroke performance of children. J Sports Sci Med 2013;12:323-31.

5 Pluim BM, Fuller CW, Batt ME, et al. Conensus statement on epidemiological studies of medical conditions in tennis, April 2009. Br I Sports Med 2009:43:893-7.

6 Sell $K$, Hainline B, Yorio $M$, et al. Injury trend analysis from the US Open Championships between 1994 and 2009. Br J Sports Med 2014;48:546-51.

7 Morante SM, Brotherhood JR. Air temperature and physiological responses during competitive singles tennis. Br J Sports Med 2007;41:773-8.

8 Hornery DJ, Farrow D, Mujika I, et al. An integrated physiological and performance profile of professional tennis. Br J Sports Med 2007;41:531-6.

9 Périard J, Racinais S, Knez W, et al. Thermal, physiological and perceptual strain mediate alterations in match-play tennis under heat stress. Br J Sports Med 2014;48:i32-8.

10 Morante SM, Brotherhood JR. Thermoregulatory responses during competitive singles tennis. $\mathrm{Br} J$ Sports Med 2008:42:736-41. 